\title{
A OBRA TARDIA DE LUKÁCS E OS REVEZES DE SEU ITINERÁRIO INTELECTUAL
}

Ester VAISMAN ${ }^{1}$

- RESUMO: O objetivo principal do presente artigo é indicar as principais características da obra tardia de G. Lukács, em especial, Para uma Ontologia do Ser Social. Pretende-se ainda tecer alguns comentários sobre sua trajetória intelectual.

- PALAVRAS-CHAVES: Lukács; Ontologia; Marxismo.

Segundo Tertulian (1971, p.15), Lukács se tornou a personalidade mais marcante da cultura marxista contemporânea. A esse respeito, na introdução do ensaio "O que é Marxismo Ortodoxo" (1919), publicado em História e Consciência de Classe (1923), ainda segundo Tertulian, Lukács formulou uma tese que revelou a sua orientação teórica básica desde o tempo de transição ao marxismo. Nele se referiu às discussões que animavam os círculos intelectuais da época em torno da definição autêntica de "marxismo ortodoxo". Em sua tese, ele sustentava que um marxista sério poderia aceitar, em princípio, a título de hipótese, a inexatidão de todas as afirmações particulares de Marx e reconhecer a necessidade de substituí-las por novos resultados da pesquisa sem deixar um só instante de ser um marxista ortodoxo. Afirmação paradoxal que representava uma atitude polêmica diante de uma concepção "dogmática" do marxismo. O marxismo autêntico não podia ser identificado a uma adesão e a uma fidelidade automáticas aos resultados da pesquisa de Marx, à "fé" em uma tese ou em outra, à exegese de uma criação "sagrada". Em se tratando do marxismo, a ortodoxia tinha

1 Professora Associada do Departamento de Filosofia e do Programa de Pós-Graduação em Filosofia da Universidade Federal de Minas Gerais-UFMG. Artigo recebido em ago/07 e aprovado em dez/ 07. 
exclusivamente a ver com o problema do método. Distinção que poderia parecer muito sutil ou simplesmente não fundamentada. Mas a afirmação tinha por objetivo sublinhar a dimensão filosófica do marxismo. Enfim, Lukács revelava uma recusa à tese da infalibilidade de toda certeza de tipo dogmático ou escolástico. Assim, em princípio todo resultado particular da pesquisa é suscetível de ser completado, modificado ou enriquecido. A ortodoxia em matéria de marxismo significava afirmar que Marx havia encontrado um método de pesquisa adequado, método que poderia ser desenvolvido, aperfeiçoado ou aprofundado. Visava, assim, sublinhar a natureza filosófica desse método e seu não-dogmatismo fundamental.

Ainda conforme Tertulian, por outro lado, a simples "posse" de um instrumento superior não é por si garantia de uma superioridade cultural e, nesse sentido, em uma determinada ocasião, Lukács veio a afirmar que Montaigne será mais interessante que um marxista medíocre.

Mas uma questão permanece tendo em vista sua obra publicada postumamente: Por que Lukács insiste em tratar de um tema tão inusual em sua obra da maturidade, a possível existência de uma ontologia em Marx? Por uma questão que fatalmente foi recebida com grande estranheza, até por seus discípulos mais diletos? Uma questão que suscitou e vem suscitando recusa imediata de todos os lados, a desaprovação in limini de quantos se dizem interessados por assuntos do tipo, que a entenderiam por inadmissível, por que insistir nesse problema "exótico"?

É forçoso reconhecer, antes de mais nada, que o século XX assumiu ou enfrentou o pensamento de Marx a partir do padrão gnosiológico, sem se interrogar se o mesmo era compatível com tal abordagem, supôs que o fosse, com base nos pressupostos da cientificidade corrente. Por outro lado, essa primeira suposição remete a uma segunda, ao do acriticismo contemporâneo em geral, por meio do qual a cientificidade repousa e tem de repousar sobre algum tipo de fundamentação gnosiológica (teoria do conhecimento, lógica ou epistemologia).

Não é o caso aqui de retomar em detalhe a extensa e sinuosa trajetória intelectual do autor. Em um artigo, desde logo, valendo-me, mais uma vez do testemunho de Tertulian, indiquei que "a evolução intelectual de Georg Lukács oferece uma imagem singular da formação e do devir de uma personalidade nas condições agitadas de um século não menos singular, por sua complexidade e pelo caráter dramático de sua história" (VAISMAN, 2005; TERTULIAN, 1971, p.15).

A dificuldade de determinar em poucas linhas o cerne teórico de Lukács tanto antes de sua adesão ao marxismo, e suas possíveis repercussões, como depois, se deve também ao fato de que o autor "passou por experiências espirituais as mais variadas e heterogêneas" (ibidem), de tal modo que uma das questões polêmicas é aquela que diz respeito às conti- 
nuidades e descontinuidades de seu pensamento. Também não é o caso aqui de nos delongarmos sobre esse importante tema, mas não poderíamos deixar de referir a tese polêmica "daqueles que consideram o 'verdadeiro Lukács' aquele das obras de juventude e que a fase de maturidade de sua obra, isto é, a fase rigorosamente marxista, constituiria uma involução evidente" (ibidem). Ademais, é fundamental referir um outro problema, sempre lembrado e vinculado à trajetória polêmica do autor: suas "autocríticas". Ainda que não seja o momento mais adequado para discutirmos esse problema, seria interessante focalizar o assunto de outro ponto de vista, talvez mais fecundo, indagando o seguinte:

que outro pensador contemporâneo foi capaz de renunciar crítica e deliberadamente, como ele fez por diversas vezes, ao prestígio de obras consagradas? Renúncia que chegou ao total divórcio delas, a ponto mesmo de manifestar completa desidentidade autoral por textos que teriam feito, cada um de per si, a inconfessa e sempre almejada glória de carreira de qualquer um, inclusive dos melhores e mais respeitáveis. Esse desapego, sinônimo de enorme exigência para consigo mesmo, que nunca declinou em arrogância ou pedantismo, nem em autoproclamações de méritos ou em bravatas de auto-suficiência, em que pese a imensa solidão teórica a que esteve constrangido seu trabalho. (VAISMAN, 2005, p.294)

Georg Lukács nasceu no ano de 1885, no bairro de Leopolstadt, em Budapeste, conforme nos informa o autor em seu Pensamento Vivido - Autobiografia em forma de diálogo. ${ }^{2}$ Seu primeiro livro, publicado em 1911, recebeu o título de A História do Desenvolvimento do Drama Moderno, tendo recebido à época um prêmio literário. Nesse passo em plena juventude, o que o autor buscara era "uma forma de interpretação das manifestações literárias que não fosse uma mera abstração de seus conteúdos peculiares. Donde, na contraposição teórica em que se encontrava e sob a aderência ao neokantismo, não ter ido além, naquela época, da equação armada em His-

2 Trata-se de uma entrevista a István Eörsi e Erzsébet Vézer, a partir de um esquema escrito por Lukács. Eörsi em uma nota inicial esclarece o leitor: "Quando Georg Lukács foi informado de sua doença fatal, emprendeu esforços extraordinários para concluir rapidamente as correções da obra Para uma Ontologia do Ser Social. O rápido agravamento de seu estado o impediu, no entanto, de executar esse trabalho para ele tão importante, com a intensidade a que estava acostumado. Nessa época, ele se pôs a escrever o esboço sobre sua vida, em parte devido ao menor desgaste teórico, em parte para, assim, satisfazer um desejo de sua falecida mulher. Depois que o esboço ficou pronto, ficou claro que não teria forças para redigir. A própria atividade de escrever mostrou-se tarefa que ultrapassava cada vez mais suas forças físicas. Entretanto, como não suportaria viver sem trabalhar, seguiu o conselho de seus alunos mais íntimos e contou sua vida em conversas gravadas ao responder, em crescente decadência física, às perguntas que baseadas no seu esboÇo biográfico, Erszébet Vezér e eu lhe fazíamos". (LUKÁCS, 1999, p.25). Edição traduzida diretamente do original alemão (LUKÁCS, 1981). Há também a edição francesa (LUKÁCS, 1986) e a italiana (LUKÁCS, 1983). 
tória da Evolução do Drama Moderno: a da pura síntese intelectual entre sociologia e estética, sob amparo e sustentação do pensamento de Simmel, em lugar de partir 'das relações diretas e reais entre a sociedade e a literatura', como dirá no Prefácio a Arte e Sociedade. Onde afirma também que 'não pode surpreender que de uma postura tão artificiosa tenham derivado construções abstratas', sempre insatisfatórias, até mesmo quando atinam com alguma determinação verdadeira" (idem, p.295-6).

Contudo, foi somente com a publicação de A Alma e as Formas (1911) que o filósofo húngaro "chamou a atenção de diversos membros da elite européia"./.../ "O último ensaio do livro...que muitos comentadores consideram como texto capital desse conjunto - foi consagrado à apologia da tragédia. Aos olhos do jovem Lukács, a tragédia aparecia como a encarnação levada às últimas conseqüências da vida essencializada, como o modo supremo de articulação desta forma...na qual ele via a condição inalienável da verdadeira arte" (TERTULIAN, 1971, p.17).

Na seqüência, publica A Teoria do Romance (1914/15, no Brasil LUKÁCS, 2000), que ao lado de A Alma e as Formas, representa o trânsito lukacsiano de Kant a Hegel que culmina na última. É o percurso que o leva, sem abandonar o território das assim chamadas ciências do espírito (Dilthey, Simmel, Weber), da filosofia e da nascente sociologia alemã de Simmel para uma forma da ciência do espírito acoplada ou traspassada pelo hegelianismo, responsável pela urdidura de A Alma E As Formas e com acentuação maior de A Teoria do Romance. Ademais, essas obras surgiram sob o influxo direto ou indireto, aqui não importa, do "esteticismo da filosofia da vida (Lebensphilosophie), que predominava no pensamento alemão no início do século passado" (TERTULIAN, 1971, p.20).

O estalar da guerra de 14 e seu efeito sobre a intelectualidade de esquerda, ao ser assumida pela social-democracia, é que determinam o projeto de redação de A Teoria do Romance. Esta "nasceu de um estado de espírito de permanente desespero diante da situação mundial", diz Lukács (1975, p.182), que por mais de uma vez lançou mão de uma fórmula de Fichte para caracterizar a imagem que nutria daquele tempo: "época da pecaminosidade consumada" (LUKÁCS, 1999, p.49). Essa visão infernal de uma Europa sem brechas e sem horizontes, tecida de pessimismo eticamente modulado, faz do Lukács de A Teoria do Romance um utópico primitivo, para utilizar uma expressão quase idêntica de seu próprio uso. De tal sorte que ele pode afirmar: "A Teoria do Romance não é conservadora, mas destruidora" (idem, 1975, p.49). E de forma mais concreta: "metodologicamente, é um livro de história do espírito. Mas acho que é o único livro de história do espírito que não é de direita. Do ponto de vista moral, considero toda aquela época condenável e, na minha concepção, a arte é boa quando se opõe a esse decurso" (idem, 1999, p.49). 
Não é possível aqui entrar em maiores detalhes sobre essa importante fase da vida do autor, mas é necessário aduzir que "o devenir intelectual de Lukács apresenta um interesse único, possuindo valor paradigmático para o destino da intelectualidade européia do século XX" (TERTULIAN, 1971, p.25).

Alguns intérpretes de Lukács, como Oldrini (2002) e Tertulian (2002), consideram que a fase de maturidade de Lukács tem início em 1930, data a partir da qual o filósofo passa a se dedicar aos seus estudos sobre a arte, tendo como orientação uma chave analítica fundada no pensamento de Marx. Oldrini, buscando descobrir o momento em que tem início o processo que leva Lukács à redação de sua obra postumamente publicada, se vale de depoimentos do crítico soviético Michail Lifschitz ${ }^{3}$ e dos húngaros István Hermann, que tinha sido um dos primeiros alunos de Lukács, e de László Szikai, diretor do Arquivo Lukács de Budapeste. Tais depoimentos "têm insistido com ênfase particular na 'importância histórica' da virada dos anos 1930, no fato de que - sem sombra de dúvida - exatamente ali, em Moscou, é que se forma o Lukács maduro" (OLDRINI, 2002, p.52-3). É sabido que no primeiro turno dos exílios em Moscou, que ocorreu no início do ano de 1930, ao deixar o exílio em Viena, Lukács trabalha com Riazanov, que então cuidava da edição dos manuscritos juvenis de Marx e empreendia a publicação da MEGA, que restou incompleta com sua expulsão em 1931 do PCUS e posterior desaparecimento no bojo dos expurgos stalinistas. Foi uma experiência mais do que invulgar, provavelmente, responsável por sua inflexão em relação ao pensamento marxiano, e da qual ele se recordava com grande entusiasmo até o fim da vida, como por exemplo, na entrevista a New Left Review em 1968: "Ouando estive em Moscou, em 1930, Riazanov me mostrou os manuscritos de Marx elaborados em Paris em 1844. Você pode imaginar meu excitamento: a leitura desses manuscritos mudou toda a minha relação com o marxismo e transformou minha perspectiva filosófica" (LUKÁCS, 1981b, p.49; trata-se de entrevista concedida à sucursal da New Left Review em Budapeste em 1968 e publicada em 1971, no número 68). De acordo com Oldrini essa virada tem caráter ontológico, na medida em que se fundamenta na crítica de Marx à filosofia especulativa de Hegel,

3 Esteta e filósofo com quem Lukács conviveu no primeiro dos seus exílios na União Soviética. No Prefácio a seu volume Arte e Sociedade, publicado em Budapest no ano de 1968, ele declara: "No Instituto Marx-Engels, conheci e trabalhei com Michail Lifschitz, com quem, no curso de longos e amigáveis colóquios, debati as questões fundamentais do Marxismo. O resultado teórico mais importante desta clarificação foi o reconhecimento da existência de uma estética marxista autônoma e unitária. Esta afirmação, indiscutível hoje em dia, parecia no início dos anos trinta um paradoxo até para muitos marxistas" (LUKÁCS, 1981a, v.I, p.11). Neste campo importa lembrar, imperavam ainda as concepções próprias ao quadro de idéias formulado pela II Internacional. 
em que Marx, influenciado, em parte, pelos pequenos escritos de Feuerbach, faz o reconhecimento da objetividade enquanto propriedade originária de todo ente. ${ }^{4}$ Oldrini considera, nesse sentido, que "as linhas diretizes da investigação lukácsiana após os anos 1930 devem imediatamente à teoria materialista da objetividade", contudo isso não significa necessariamente "que se devam deixar de lado", na análise desse longo período que desemboca em Para uma Ontologia do Ser Social, "os inconvenientes e os limites que derivam da ausência como fundamento, de um explícito projeto ontológico. Nesse momento, em Lukács, esse projeto está completamente ausente" (OLDRINI, 2002, p.67). Além disso, é necessário advertir para o fato que tal "virada", por assim dizer, embora apresente diferenças substanciais com seus textos juvenis, não é "fruto de uma brusca e inesperada inversão de rota, de uma reviravolta que se teria verificado de improviso, sem preparação, na última década da vida do filósofo. Pelo contrário, por trás dela há uma longa história, que merece atenção" (idem, p.50). Essas fases intermediárias de seu pensamento que incluem, segundo Oldrini, "por exemplo, os escritos berlinenses ou moscovitas, aqueles de volta à Hungria" (ibidem), merecem um estudo mais cuidadoso, sem isolá-los do contexto mais amplo da obra. Evidentemente, tal intento escapa aos limites da presente proposta de trabalho. O que importa aqui é identificar os móveis teóricos que relacionam sua grande Estética com o trabalho derradeiro.

Ao assinalarmos a provável existência de um fio condutor, principalmente entre a Estética e a Ontologia, não resulta de imediato a conclusão que Lukács tenha aderido, sem mais à própria expressão, ainda que, como afirma Oldrini "mesmo lá onde a coisa, o nexo conceitual já exista em germe falta a palavra para expimi-lo" (idem, p.67). Em verdade, Lukács nutria sérias desconfianças e suspeitas em relação à própria palavra, resistindo em utilizá-la; "para ele, tomando a conotação que lhe fora conferida por Heidegger, ela só tem um valor negativo" (ibidem). Entretanto, ao entrar em contato com a obra de Ernst Bloch, Questões Fundamentais da Filosofia. Pela ontologia do ainda-não-ser (noch-nicht-seins), publicada em 1961 e com a volumosa obra de Nicolai Hartmann sobre Ontologia, há uma mudança de postura do autor em relação à palavra. Tertulian, citado por Oldrini, chega mesmo a afirmar "que os escritos ontológicos de Hartmann tiveram o papel

4 Lukács (1999, p.145) posiciona-se a respeito do seguinte modo: "Marx elaborou principalmente e esta eu considero a parte mais importante da teoria marxiana - a tese segundo a qual a categoria fundamental do ser social, e isto vale para todo ser, é que ele é histórico. Nos manuscritos parisienses, Marx diz que só há uma única ciência, isto é, a história, e até acrescenta: 'Um ser não objetivo é um não ser'. Ou seja, não pode existir uma coisa que não tenha qualidades categoriais. Existir, portanto, significa que algo existe numa objetividade de determinada forma, isto é, a objetividade de forma determinada constitui aquela categoria à qual o ser em questão pertence". 
de catalisador na reflexão de Lukács; eles lhe inculcaram, com certeza, a idéia de buscar na ontologia e nas suas categorias as bases de seu pensamento" (Tertulian apud idem, p.68).

Desse modo, a abordagem da própria Estética muda de configuração: apesar de, cronologicamente, ter sido elaborada antes da Ontologia, há claros indícios que tornam factível a hipótese de que, em termos lógicos, os problemas ontológicos já estavam presentes, mesmo que dita expressão não tenha sido utilizada, seja porque Lukács a associava com o existencialismo, seja porque ele próprio não havia se dado conta da possibilidade de uma ontologia em bases materialistas. O fato é que, no entanto, "a tese de que a obra de arte 'está lá', que ela existe anteriormente à análise de suas condições de possibilidade não representa de fato uma 'novidade' do último Lukács" (idem, p.70). De fato, a partir do depoimento do próprio autor constata-se esse nexo entre a análise da obra de arte que questões de ordem ontológica. No prefácio de 1969 à edição francesa de Meu Caminho até Marx, o autor afirma: "Se para a Estética, o ponto de partida filosófico consiste no fato de que a obra de arte está aí, que ela exista, a natureza social e histórica dessa existência faz com que toda problemática se desloque para uma ontologia social" (Lukács, 1971, apud idem, p.69).

Ainda é Tertulian (1986, p.11) que nos oferece uma informação preciosa acerca do momento preciso em que tem início a elaboração da última obra de Lukács: maio de 1960, data em que conforme seus planos daria início aos escritos da Ética. Contudo, "sabemos o que ocorreu depois: os trabalhos preparatórios da Ética se transformaram num volumoso manuscrito, a Ontologia do Ser Social, concebida como uma necessária introdução à obra principal" (Tertulian, 1999, p.126).

A incursão lukácsiana no debate da ontologia não é de modo algum fruto de inclinações particulares ou pessoais, mas surge do reconhecimento de que uma série de questões teóricas que deveriam ser tratadas a partir de uma nova perspectiva. As adversidades de seu tempo impunham - assim julgava o pensador húngaro - a enorme tarefa de retornar à obra de Marx, no intuito de reformular cabalmente as perspectivas teóricas vigentes, de buscar respostas aos descaminhos provocados pela vulgata stalinista que dominou quase toda a tentativa de compreensão teórica dos fenômenos mais importantes do século XX, além das graves distorções que provocara na recepção da obra de Marx.

Por isso mesmo, a última grande obra filosófica de György Lukács, Para uma Ontologia do Ser Social, constitui no interior da história do marxismo um caso à parte, uma vez que destoa do núcleo comum sobre o qual a obra de Marx foi compreendida ao longo de todo o século passado. Esta obra tem por mérito ter sido a primeira a destacar o caráter ontológico do pensamento de Marx, como já indicamos linhas acima. 
O retorno sugerido possui uma peculiaridade frente a todo o edifício teórico que se ergueu sobre a base das proposituras marxianas: é uma afirmação enfática de que "ninguém se ocupou tanto quanto Marx da ontologia do ser social", como já sublinhamos anteriormente. Parte da denúncia de que o caráter ontológico do pensamento marxiano ficou obscurecido pela rigidez dogmática em que o marxismo se viu imerso e que rechaçava toda e qualquer discussão acerca da ontologia, qualificando-a de idealista e ou simplesmente metafísica. Na verdade, como o próprio Lukács sugere, esta rigidez nada mais é do que uma vertente específica das reflexões lógicoepistemológicas que passaram a dominar todo o cenário da filosofia desde o séc. XVII, ${ }^{5}$ que combatem vigorosamente "toda tentativa de basear sobre o ser o pensamento filosófico em torno do mundo", afirmando "como não científica toda pergunta em relação ao ser" (LUKÁCS, 1984, p.7; 1990, t.I, p.3). Não importa o quão antagônicas possam ser em relação a seus princípios filosóficos, ambas são perspectivas enrijecidas e reduzidas pelas mesmas amarras, uma vez que se fundam no interior das discussões lógicognosiológicas e, precisamente por isso, ambas estão incapacitadas de perceber que o cerne estruturador do pensamento marxiano são lineamentos ontológicos acerca do ser social.

Todo o vigor dos escritos ontológicos de Lukács possui duas direções básicas: volta-se contra as leituras mecanicistas provenientes principalmente do stalinismo e do marxismo vulgar ao mesmo tempo em que procura combater a crítica dos adversários de Marx, demonstrando como a incompreensão - e mesmo a recusa - de toda e qualquer ontologia encontrase circunscrita em necessidades prementes da própria configuração da sociedade capitalista:

O combate sugerido por Lukács ao predomínio das reflexões lógicoepistemológicas tem, portanto, a perspectiva que concilia a posição teórica com a necessidade prática. Contra o predomínio manipulatório a que se viu reduzida a ciência no mundo do capital, a ontologia recoloca o problema filosófico essencial do ser e do destino do homem e sua auto-constituição contraditória.

A percepção de uma ontologia em Marx fornece a ele os elementos passíveis de estabelecer de uma vez por todas a ruptura com a gnosiologia. As reflexões de Lukács partem da crítica fundamental que postula que, em

5 "Após 1848, depois do declínio da filosofia hegeliana e, sobretudo, quando começa a marcha triunfal do neokantismo e do positivismo, os problemas ontológicos não são mais compreendidos. O neokantismo elimina da filosofia a incognoscível coisa em si, enquanto que para o positivismo a percepção subjetiva do mundo coincide com a sua realidade" (LUKÁCS, 1984, p.574; 1990, t.I, p.277). 
Marx, "o tipo e o sentido das abstrações, dos experimentos ideais, são determinados não a partir de pontos de vista gnosiológicos ou metodológicos (e tanto menos lógicos), mas a partir da própria coisa, isto é, da essência ontológica da matéria tratada" (idem, p.596; idem, p.302).

Revela-se nessas palavras o reconhecimento de uma fecunda inflexão do pensamento de Marx em relação a tudo o que foi produzido pela filosofia até então: "o objeto da ontologia marxista, diferentemente da ontologia clássica e subseqüente, é o que existe realmente: a tarefa é a de investigar o ente com a preocupação de compreender o seu ser e encontrar os diversos graus e as diversas conexões em seu interior". Instaura-se a partir desta determinação uma inflexão com os padrões científicos predominantes desde do século XVII. A novidade do pensamento de Marx deve ser entendida sob as bases de:

uma estrutura de caráter completamente novo: uma cientificidade que no processo de generalização, nunca abandona este nível (existência em-si), e que não obstante, em cada singular adequação aos fatos, em cada reprodução ideal de um nexo concreto, examina continuamente a totalidade do ser social e deste modo sopesa continuamente a realidade e o significado de cada fenômeno singular; uma consideração ontológico-filosófica da realidade existente em si que não vaga por sobre os fenômenos hipostasiando as abstrações, mas ao contrário, se põe, criticamente e autocriticamente no mais elevado nível de consciência, só para tomar cada existente na plena forma de ser que lhe é própria, que é específica propriamente deste. Nós cremos que Marx criou assim uma nova forma tanto de cientificidade geral quanto de ontologia, que é destinada no futuro a superar a constituição profundamente problemática, não obstante toda a riqueza dos fatos descobertos, da cientificidade moderna. (idem, p.572; idem, p.275)

Esta nova caracterização da cientificidade é definida de um modo simples, porém pleno de conseqüências: as "categorias são formas e determinações da existência". Afirmar isto significa dizer, por um lado, que em tal propositura as categorias e conexões próprias ao ser assumem para o pensamento caráter de metro crítico no processo de construção das abstrações.

E arrematando de forma conclusiva, Lukács diferencia a "velha filosofia" da filosofia de Marx:

o marxismo distingue-se em termos extremamente nítidos das concepções do mundo precedentes: no marxismo o ser categorial da coisa constitui todo o ser da coisa, enquanto nas velhas filosofias o ser categorial era a categoria fundamental no interior da qual se desenvolviam as categorias da realidade. Não é que a história se desenvolva no interior do sistema das categorias, mas ao contrário, a história é a transformação do sistema das categorias. As categorias são, em suma, formas do ser. (LUKÁCS, 1986, p.85)

O ser não é uma categoria abstrata, na medida em que é compreendido como totalidade concreta dialeticamente articulada em totalidades par- 
ciais. Esta estrutura constitutiva do ser, a que Lukács designa como um "complexo de complexos" - tomando de empréstimo a terminologia de Nicolai Hartmann - apresenta-se sempre por meio de uma intrincada interação dos elementos no interior de cada complexo. O complexo no interior desta perspectiva é compreendido e determinado como um conjunto articulado de categorias que se determinam reciprocamente, e estruturado de forma decisiva por uma categoria que atua como momento preponderante em seu interior. Desse modo a "universal processualidade do ser deriva não somente da complicada interação dos 'elementos' (complexos) no interior de cada complexo e dos complexos entre si, mas da presença cada vez de um übergreifendes Moment que fornece a direção objetiva do processo, o qual se configura por isso como um processo histórico" (SCARPONI, 1976, p.XIII).

Este enfrentamento - teórico e prático - forma a base do argumento que adverte para a necessidade de retorno a Marx, sem as peias erguidas pelo marxismo em geral. Trata-se de varrer das páginas da obra marxiana, uma discussão totalmente estranha à sua letra: afirmações que acusam a existência em Marx de um determinismo unívoco, proveniente da esfera da economia, que absolutiza a potência do fator econômico legando ao segundo plano a eficácia dos outros complexos da vida social. Ao contrário de um determinismo unívoco da esfera econômica sobre as outras instâncias da sociabilidade, como acusa grande parte de seus adversários, o cerne estruturador do pensamento econômico de Marx se funda na concepção da determinação recíproca das categorias que compõem o complexo do ser social. Nas palavras do próprio autor:

Este peculiar, paradoxal, raramente compreendido, método dialético, repousa na já acenada convicção de Marx, segundo a qual, no ser social o econômico e o extra-econômico continuamente se convertem um no outro, estando em uma insuprimível interação recíproca, da qual, como mostramos, não deriva nem um desenvolvimento histórico extraordinário privado de leis, nem uma dominação mecânica 'imposta por lei' do econômico abstrato e puro. (LUKÁCS, 1984, p.585; 1990, t.I, p.290-1)

São, portanto, momentos que se apresentam permanentemente em um estado de determinação reflexiva. É a interação e inter-relação destes momentos que constitui a estrutura sobre a qual se move e dinamiza o processo de socialização do homem. As categorias da produção e reprodução da vida - esfera econômica - desenvolvem a função motor central desta dinâmica, todavia, só podem se desenvolver sob a forma de um momento ontologicamente primário de uma interação entre os complexos que vêm a existir na dialética objetiva entre acaso e necessidade. A base econômica permanece sempre como o momento preponderante, no entanto, isso não elimina a rela- 
tiva autonomia das superestruturas, que se expressa de maneira definitiva na dialética de mútua reciprocidade determinativa existente entre estas e a esfera da economia. Portanto, as esferas superestruturais da sociedade não são simples epifenômenos da estrutura econômica. Longe de constituírem um reflexo passivo, estas estruturas podem agir (ou retroagir) sobre a base material em maior ou menor grau, sempre, entretanto, no interior das "condições, possibilidades ou impedimentos" que esta lhe determina.

O que caracteriza e determina a especificidade da atividade humana é o fato de ser uma "atividade posta", ou seja, é a configuração objetiva de um fim previamente ideado - pôr teleológico. O trabalho passa a ser entendido assim como a unidade entre o pôr efetivo de uma dada objetividade e a atividade ideal prévia diretamente regida e mediada por uma finalidade específica. Neste sentido, Lukács define o resultado final do trabalho como uma "causalidade posta", o que significa dizer que se trata de uma causalidade que foi posta em movimento pela mediação de um fim humanamente configurado. Na atividade laborativa estas duas categorias, embora antagônicas e heterogêneas, formam uma unidade no interior do complexo. Portanto, de um lado, a causalidade posta, e de outro o pôr teleológico, constituem, sob a forma da determinação reflexiva, o fundamento ontológico da dinamicidade de complexos próprios apenas ao homem, na medida em que a teleologia é uma categoria existente somente no âmbito do ser social. Deste modo, definindo o pôr teleológico como célula geratriz da vida social, e vislumbrando no seu desenvolvimento e complexificação o conteúdo dinâmico da totalidade social, Lukács impossibilita a confusão entre as diretrizes e princípios que regem a vida da natureza e a vida da sociedade: "a primeira é dominada pela causalidade espontânea, não teleológica por definição, enquanto a segunda é constituída por obra dos atos finalistas dos indivíduos" (TERTULIAN, 1990, p.XX).

Após estas determinações sobre os fundamentos genéticos da ontologia do ser social, Lukács demonstra como estes mesmos atos teleológicos podem aparecer de forma diferenciada quando se considera o objeto sobre o qual incidem suas ações. Entre esses atos, a diferença fundamental se refere fundamentalmente ao objeto sobre o qual exercem sua ação. Os atos teleológicos primários incidem de forma imediata sobre um dado objeto ou elemento natural, enquanto os atos teleológicos secundários têm como finalidade a consciência de outros homens, ou seja, "não são mais intervenções imediatas sobre objetos da natureza, mas intencionam provocar estas intervenções por parte de outras pessoas" (LUKÁCS, 1984, p.46; 1990, t.II, p.56). Desse modo, percebe-se também em que esfera da vida social, sempre atada à prática, se encontra a esfera da educação e suas conseqüências.

É a análise destas formas distintas dos atos teleológicos que nos auxilia a compreender o processo de desenvolvimento das fases superiores a partir 
da forma originária do trabalho. A dinâmica inerente às interações categoriais do trabalho não apenas instaura a origem humana como também determina a dinâmica das formas superiores da prática social. Nas formas superiores de sociedade elas ocupam um lugar de destaque, assumindo o papel preponderante na dinâmica deste processo. Os assim denominados atos teleológicos secundários tornam-se mais "desmaterializados" uma vez que se desvinculam da relação direta com o momento material da prática social. São estes atos, também designados por atos socio-teleológicos, que mais tarde dão origem a dimensões importantes da prática social, tais como a ética, a ideologia, a educação e inclusive - e esta é uma questão crucial para Lukács - a partir dela podemos vislumbrar a gênese das ações políticas.

Tanto a questão do trabalho quanto a complexificação da dinâmica da sociedade humana com o advento das formas superiores da vida social como a formação humana, entendidos no sentido mais lato do termo, são tratadas prevalentemente a partir da determinação recíproca e da superação da heterogeneidade entre teleologia e causalidade. Essas categorias formam, no interior das elaborações lukácsianas a base analítica de toda e qualquer ação do ser social. Nesse mesmo diapasão, identificamos outra tese lukácsiana: todo o processo social é posto em movimento por meio das ações teleológicas individuais, mas que em sua totalidade estes atos não possuem uma finalidade determinada, resulta daí todo um movimento que opera por meio de nexos causais espontâneos. Afirmação que nos leva, portanto - e aqui convém ressaltar esta determinação com toda a clareza -, a entender que no plano da totalidade do ser social está presente toda uma malha de nexos que atuam sob a forma de uma causalidade social. Fato que leva o pensador húngaro, com essas determinações, a assumir uma posição contrária a tendências no interior do próprio marxismo e contra ainda a filosofia hegeliana, ao asseverar a inexistência de uma teleologia na história.

VAISMAN, Ester. Lukács latest works and the problems with his intellectual intinerary. Trans/Form/Ação, (São Paulo), v.30(2), 2007, p.247-259.

- ABSTRACT: This article's main purpose is to point out the most striking features on G. Lukács latest works, focusing particularly on The Ontology of Social Being. It will also elaborate on his intellectual trajectory.

- KEYWORDS: Lukács; Ontology; Marxism. 


\section{Referências bibliográficas}

FEUERBACH. Princípios da Filosofia do Futuro. Lisboa: Edições 70, s.d.

LUKÁCS, G. Arte e Societá. Roma: Editori Riuniti, 1981a.

"Democracia Burguesa, Democracia Socialista e outras questões". In: Nova Escrita/Ensaio. São Paulo: Editora Escrita, ano IV, n.8, 1981b.

"Diálogo sobre o pensamento vivido". In: Revista Ensaio, n.15/16. São Paulo: Editora Ensaio, 1986a.

"Prolegomena zur Ontologie des gesellschaflitchen Seins". Zur Ontologie des gesellschaftlichen Seins, I. Halband, Luchterhand Verlag, 1984.

Gelebtes Denken - Ein Autobiographie im Dialog, Frankfurt am Main: Suhrkamp, 1981.

Pensamento Vivido. Santo André: Estudos e Edições Ad Hominem e Viçosa: Editora UFV, 1999.

. Pensée Vécue- Mémoires Parlés. Paris: L' Arche Éditeur, 1986b.

. Pensiero Vissuto - Autobiografia in Forma di Dialogo. Roma: Editori Riuniti, 1983.

. Per l'Ontologia dell'Essere Sociale. Roma: Editori Riuniti, 1976.

. "Prólogo". La Teoria de la Novela. In: Obras Completas. vol. I. Barcelona:

Ediciones Grijalbo, 1975.

. Utam Marxhoz. Budapest, 1971.

. Prolegomeni All'Ontolologia dell'Essere Sociale - Questioni di principio di un'ontologia oggi divenuta possible. Milano: Guerini \& Associati, 1990.

. Teoria do romance. São Paulo: Duas Cidades/Editora Contraponto, 2000.

. Zur Ontologie des gesellschaftlichen Seins. I. Halband, Luchterhand Verlag, 1984.

OLDRINI, G. "Em busca das raízes da ontologia (marxista) de Lukács". In: Lukács e a Atualidade do Marxismo. São Paulo: Boitempo Editorial, 2002.

SCARPONI, A. "Prefácio". In: LUKÁCS, 1976.

TERTULIAN, N. "Introduzione". In: LUKÁCS, 1976.

"L'Évolution de la Pensée de Georg Lukács". In: L'Homme et la Societé. n.20, avril,-mai-juin. Paris: Editions Anthropos, 1971.

"Lukács Hoje". In: Lukács e a Atualidade do Marxismo. São Paulo: Boitempo Editorial, 2002.

"O Grande Projeto da Ética". In: Ensaios Ad Hominem n.1, tomo I. Santo André: Estudos e Edições Ad Hominem, 1999.

Lukács: La rinascita dell, ontologia. Roma: Editori Riuniti, 1986.

VAISMAN, E. "O 'Jovem' Lukács: Trágico, Utópico, Romântico?”. In: Revista Kriterion, n.112, 2005. 